Pathologie végétale (synthèse)

\title{
Les phytoalexines et leur intervention dans la résistance hypersensible aux champignons phytopathogènes
}

\author{
T. Rouxel \\ INRA, Station de pathologie végétale, route de Saint-Cyr, 78026 Versailles Cedex, France
}

(reçu le 3 janvier 1989, accepté le 13 avril 1989)

\begin{abstract}
Résumé - La réaction hypersensible est un mécanisme de défense des plantes caractérisé par une nécrose pigmentée, touchant peu de cellules, et se développant rapidement au niveau du point de pénétration du champignon phytopathogène. Elle entraîne généralement une restriction du développement de celui-ci, et est caractéristique de plantes présentant une résistance verticale au parasite, ou un haut niveau de résistance générale. Elle ne s'exprime souvent que dans certains tissus, voire certaines cellules. La réaction hypersensible est un phénomène complexe, s'accompagnant de nombreuses modifications physiologiques et biochimiques, parmi lesquelles des perturbations de la perméabilité cellulaire, une stimulation de la production d'éthylène et une synthèse intense de phytoalexines. Composés antimicrobiens de faible poids moléculaire, ces dernières sont observées chez la plupart des dicotylédones. Leur accumulation résulte d'une activation génique spécifique et d'une synthèse de novo d'ARNm et de protéines, en réponse à une contamination, à un stress biologique (éliciteurs biotiques) ou à des stimuli abiotiques. Tous les individus d'une même espèce possèdent les gènes nécessaires à la synthèse des mêmes phytoalexines. La résistance à un micro-organisme serait liée à une accumulation plus rapide et/ou plus intense de ces métabolites. Par ailleurs, certains agents pathogènes ont la capacité de supprimer les synthèses de phytoalexines par la plante ou de détoxifier celles-ci. Lors d'une réaction hypersensible, la séquence d'événements le plus couramment observée est : mort de quelques cellules de l'hôte / accumulation de phytoalexines / mort du parasite. La mort cellulaire servirait de signal déclenchant la synthèse des phytoalexines. Celles-ci, synthétisées par les tissus sains environnants, sont concentrées dans les cellules mortes. Leur accumulation serait responsable de la restriction du développement de l'agent pathogène, voire du processus nécrotique.
\end{abstract}

phytoalexines - résistance hypersensible - champignons phytopathogènes

Summary - Phytoalexins and their involvement in the hypersensitive response to fungal pathogens. The hypersensitive response is a rapid necrosis of plant cells surrounding the infection site of the pathogen and restricting its development. Plants with major genes for resistance or a high level of general resistance usually develop a hypersensitive response in some specific tissues or cells. This reaction is the sum of many biochemical and physiological changes, including cell permeability damage, enhanced production of ethylene and accumulation of phytoalexins. Phytoalexins are low molecular weight antimicrobial compounds which have been described in most dicotyledons. Phytoalexin accumulation is initiated by infection or abiotic stresses and requires specific gene activation and de novo synthesis of mRNA and proteins. All the plants of the same species possess the genes for the synthesis of the same phytoalexins. Resistance to pathogens would then be related to the amount of their accumulation. Some pathogens are able to suppress phytoalexin synthesis or to detoxify these compounds. The hypersensitive response is usually a three-step event : plant cell death/phytoalexin accumulation/death of the pathogen. Host cell death would be the trigger for phytoalexin synthesis, and their accumulation in necrotic cells would restrict pathogen development.

phytoalexins - hypersensitive resistance - fungal pathogens

\section{Introduction}

De nombreux mécanismes permettent aux plantes de résister à la plupart des micro-organismes auxquels elles sont confrontées. Des barrières physiques préformées, telles que la cuticule recouvrant l'épiderme des organes aériens, s'opposent à leur pénétration et peuvent contenir des substances inhibant la germination des spores ou la différenciation de structures caractéristiques de l'infection. L'absence de facteurs nécessaires à la croissance ou à la reproduction du parasite, ainsi que la présence de composés antibiotiques préformés dans les tissus végétaux, sont aussi des mécanismes constitutifs favorisant la résistance. 
Par ailleurs, l'infection déclenche de nombreux mécanismes actifs visant à empêcher la pénétration du parasite dans les cellules de l'hôte (renforcement des parois cellulaires : dépôts de callose, de cellulose, de lignines, formation de papilles), à limiter son déplacement dans la plante (lignification, production de gels et de tyloses lors d'infections vasculaires) et/ou à le détruire (production d'enzymes lytiques, phytoalexines).

Nous proposons ici une mise au point sur l'un des mécanismes actifs de défense les plus étudiés, la réaction hypersensible, et l'intervention dans ce type de résistance de composés fongitoxiques, les phytoalexines.

En premier lieu, il nous semble important de préciser la définition de diverses expressions classiques utilisées en pathologie végétale.

Par le terme de parasite ou d'agent pathogène, nous désignons ici un organisme vivant sur ou dans une plante-hôte, aux dépens de l'organisme parasité (Day, 1974). Nous ne nous intéresserons ici qu'aux agents pathogènes "vi-vants" et, principalement, aux parasites de nature fongique.

La relation compatible correspond à une relation durable entre plante et micro-organisme (symbiose ou maladie) (Ellingboe, 1972). Bailey (1982b) propose de parler de période de compatibilité. Dans le cas de relation incompatible, en revanche, il n'y a pas de relation durable entre plante et agent pathogène (résistance de la plante - avirulence du parasite) (Ellingboe, 1972).

L'agressivité est caractérisée par l'importance des dommages que l'agent pathogène peut causer sur la plante-hôte. La plante lui oppose une résistance horizontale (ou générale), souvent de nature polygénique (Van der Plank, 1982). Cette résistance est incomplète et également efficace contre toutes les races de l'agent pathogène.

Enfin, la virulence concerne la capacité pour un agent pathogène à surmonter une résistance spécifique. Elle est conditionnée par des gènes de virulence en général récessifs. La plante lui oppose une résistance verticale (ou spécifique), qui se superpose à la résistance générale. La résistance verticale est de nature oligo- ou monogénique. Ces gènes, généralement dominants, confèrent une résistance absolue aux races de l'agent pathogène possédant les gènes d'avirulence correspondants (Van der Plank, 1982). Ils ne participent pas à la fonction de défense générale.

\section{La réaction hypersensible}

\section{Historique et définition}

La réaction hypersensible, souvent considérée comme la réaction de défense la plus efficace vis-à-vis des parasites, fut décrite pour la première fois par Ward (1902), puis par Marryat (1907). Les auteurs observent une nécrose rapide des cellules infectées et des cellules environnantes lors d'une attaque du brome par Puccinia recondita et du blé par $P$. striiformis. Stakman (1915) introduit le terme "hypersensitiveness" pour définir une mort anormalement rapide de cellules de blé attaquées par $P$. graminis.

Cette réaction est ensuite signalée pour de nombreuses espèces végétales, en réponse à des attaques par des champignons biotrophes ou nécrotrophes, des virus, des bactéries, des nématodes ou des insectes (Müller, 1959; Fuchs, 1976).

La réaction hypersensible est caractérisée par une nécrose pigmentée (brun sombre ou noire) se développant rapidement au point de pénétration du parasite, et touchant peu de cellules. Elle est généralement associée à une restriction du développement de l'agent pathogène (Bailey, 1983).

\section{Déterminisme génétique}

En accord avec le schéma proposé par Flor (1971), il est généralement admis que la réaction hypersensible et l'accumulation de phytoalexines résultante sont associées à l'incompatibilité dans les systèmes gène-pour-gène ${ }^{1}$ (De Wit, 1986). Certains auteurs vont jusqu'à envisager que la seule expression de la résistance verticale est la réaction hypersensible et que ce type de résistance est toujours exprimé sous cette forme (cité dans Crute et al., 1985). De nombreux exemples d'association entre résistance verticale et réaction hypersensible tendent à accréditer cette hypothèse (Tableau I).

Mais il existe aussi des résistances verticales s'exprimant sans réaction hypersensible.

Ainsi Masri et Ellingboe (1966) et Johnson et al. (1969), dans la relation entre l'orge et Erysiphe graminis, décrivent un gène conditionnant une résistance verticale (gène $\mathrm{Ml}_{\mathrm{a}}$ ), qui se manifeste à différents stades de l'infection sans réaction hypersensible systématique. Son expression a pour résultat d'inhiber fortement la formation des haustoria et de supprimer la sporulation du parasite. Selon Jorgensen et Mortensen (1977), le fait que les cellules annexes des stomates soient plus sensibles au parasite que les autres cellules épidermiques, et constituent donc une voie d'entrée privilégiée, conduirait dans ce cas à une induction de sensibilité (et à une suppression de la réaction hypersensible).

1. A noter que selon Van der Plank (1982), le parasitisme conditionné par une relation gène-pour-gène est, au moins partiellement, de type biotrophe (biotrophie stricte et hémibiotrophie). 
Tableau I. Exemple de relations gène-pour-gène dans lesquelles l'incompatibilité a été associée à la réaction hypersensible. Dans les trois derniers cas, la relation gène-pour-gène est suspectée mais n'a pas encore été prouvée.

Hôte

Triticum spp. (blé)

Solanum spp. (pomme de terre)

Linum usitatissimum (lin)

Lactuca sativa (laitue)

Lycopersicon esculentum (tomate)

Glycine max (soja)

Phaseolus vulgaris (haricot)
Agent pathogène

Références
Rohringer et al. (1979)

Slesinski et Ellingboe (1969)

Masri et Ellingboe (1966)

Doke (1982), Clarke (1983)

Coffey (1983)

Crute et Dickinson (1976),

Farrara et al. (1987)

Cladosporium fulvum

Sijpesteijn (1976), Lazarovits et Higgins (1976a, 1976b), De Wit (1977)

Keen (1971)

Harper et al. (1987)
Hohl et Suter (1976), étudiant la relation entre le cultivar Eba de pomme de terre et Phytophthora infestans, observent une réaction hypersensible caractéristique au niveau des tubercules mais non des feuilles. Les symptômes décrits à ce niveau sont similaires chez un hôte résistant et un hôte sensible.

Dans la relation entre le blé et $P$. graminis tritici, la réaction hypersensible due au gène $\mathrm{Sr} 6$ ne s'exprime que dans les cellules du mésophylle (Rohringer et al., 1979; Harder et al., 1979a). Par ailleurs, elle n'apparaît qu'à certaines températures $\left(19^{\circ} \mathrm{C}\right.$ par exemple) (Skipp et Samborski, 1974) et peut être très altérée en fonction de l'environnement génétique dans lequel le gène Sr6 est inséré (Rohringer et al., 1979).

A l'opposé, certains travaux font état de réactions de type hypersensible qui sont la conséquence de résistances considérées comme horizontales.

Dans le cas de la résistance de la pomme de terre à $P$. infestans, différents auteurs montrent que des variétés ne possédant pas de gènes conditionnant une résistance verticale sont capables, durant certaines phases de leur développement, de développer une réaction hypersensible au parasite (Thurston, 1971; Populer, 1978; Doke et Tomiyama, 1980; Wilson et Coffey, 1980; Coffey et Wilson, 1983). La même analyse s'applique au cas du couple orge/E. graminis
(Asher et Thomas, 1983). Par ailleurs, il existe des exemples de relations compatibles dans lesquelles une certaine proportion des tentatives de pénétration de l'agent pathogène entraîne une réaction de type hypersensible (Mercer et al., 1974; Asher et Thomas, 1983; Gees et Hohl, 1988). Le développement de la maladie n'est cependant pas retardé en raison du faible taux de cellules réagissant de cette manière (Mercer et al., 1974).

De plus, une résistance hypersensible peut parfois être induite chez des plantes sensibles à un parasite, lors de traitements par des «fongicides de troisième génération»1 (par exemple : Cartwright et al., 1980; Bompeix et al., 1981; Mansfield, 1982).

\section{En conclusion}

Dans le cas de gènes conditionnant une résistance verticale

Keen (1982) suppose que certains de ces gènes s'expriment beaucoup plus lentement que les gènes "classiques". Cela expliquerait que le profil habituel de la réaction hypersensible ne soit pas observé dans tous les cas. Ainsi, dans la

\footnotetext{
1. Les «fongicides de troisième génération" présentent la caractéristique d'être plus actifs contre l'agent pathogène in vivo qu'in vitro. Ils agiraient en stimulant les réponses de la plante lors d'une infection parasitaire (Bompeix et al., 1981).
} 
relation entre le blé et $P$. graminis tritici, les gènes $\mathrm{Sr} 8$ et $\mathrm{Sr} 22$ conditionnent une nécrose bloquante tardive en périphérie de la colonie (Rohringer et al., 1979).

Par ailleurs, il semble exister une certaine spécialisation tissulaire ou cellullaire rendant certains tissus (ou certaines cellules) seuls capables de réagir de façon hypersensible (Ingram, 1982). Dans cette optique, Doke (1982) note, sur tubercules de pomme de terre, en réponse à une attaque par une race incompatible de $P$. infestans, que certaines cellules ont la capacité de réagir rapidement, d'autres plus lentement, et d'autres pas du tout'1.

Dans le cas de gènes conditionnant une résistance horizontale

Gees et Hohl (1988) observent que des plantes à haut niveau de résistance générale peuvent développer une réaction morphologiquement impossible à distinguer de la réaction hypersensible de plantes dont la résistance est de type vertical. Asher et Thomas (1983) estiment qu'il n'y a pas de différence fondamentale entre résistance générale et résistance spécifique, si ce n'est dans l'intensité de l'expression des gènes les conditionnant (Gracen, 1982).

\section{Réponse à deux niveaux}

Keen $(1982,1986)$ envisage une réponse du végétal à 2 niveaux : le premier concerne une reconnaissance non spécifique d'un agent pathogène par une espèce végétale et conduit à une résistance horizontale pouvant s'exprimer sous forme de réaction hypersensible générale. Le second est lié à une relation gène-pour-gène et une reconnaissance spécifique entraîne l'expression, sous forme de réaction hypersensible, de gènes de résistance verticale.

Pour Doke et al. (1987) tous les cultivars, possédant ou non des gènes de résistance spécifique, auraient le potentiel génétique pour toutes les composantes de la réaction hypersensible (Gracen, 1982). Toutes les races d'un agent pathogène auraient, par ailleurs, le potentiel d'élicitation nécessaire pour induire la réaction hypersensible chez tous les cultivars.

\section{Mécanismes de l'expression de la réaction hypersensible}

La réaction hypersensible est un phénomène actif, dont les mécanismes de base sont souvent

1. L'interprétation de ces faits est compliquée par l'observation d'Ellingboe (1972), selon laquelle la présence d'un gène de virulence ne conditionne pas une homogénéité génique totale du parasite. En ce qui concerne les taux de germination ou les vitesses de croissance, en particulier, des différences entre les individus peuvent être notées. très mal connus. Elle est déclenchée par une "lésion métabolique initiale» (Bailey, 1982b) et s'accompagne de nombreuses modifications physiologiques et biochimiques.

La séquence d'événements conduisant à une réaction hypersensible a été particulièrement étudiée dans le cas de la relation entre les cultivars résistants de pomme de terre et des isolats avirulents de Phytophthora infestans (Doke et al., 1987). Pour ce modèle, la réaction hypersensible résulte d'au moins trois événements clés. Le premier consiste en une activation/potentialisation cellulaire antérieure à la pénétration (I). Le deuxième intervient lors de la pénétration. II s'agit de la reconnaissance par la plante de la présence du non-soi. Elle est suivie d'une mort cellulaire rapide (cette étape serait supprimée lors d'une relation compatible) (II). Le troisième correspond à l'induction de la synthèse de phytoalexines (III).

(I) Les cellules végétales peuvent répondre de façon hypersensible mais une telle réaction nécessite un préconditionnement permettant d'exprimer leur potentiel et d'acquérir une "réactivité hypersensible». Ce conditionnement serait provoqué par des stimuli provenant des spores en germination, mais pourrait aussi être assuré par une blessure. Une production d'anions superoxyde $\left(\mathrm{O}_{2}^{-}\right)$est observée immédiatement après traitement par le milieu de germination des spores du parasite, ou après blessure. Ces anions joueraient un rôle de stimulus biochimique dans la "capacitation" cellulaire. Les auteurs montrent, par ailleurs, que l'acquisition de la réactivité hypersensible est liée à des synthèses de novo de protéines.

(II) Le deuxième événement clé débute par une liaison entre des molécules de la paroi des hyphes mycéliens et des lectines de la membrane plasmique des cellules végétales, après un contact entre hyphe et membrane. Ce phénomène est observé, que les relations soient compatibles ou incompatibles. Des éliciteurs non spécifiques de la paroi fongique induiraient alors la réaction hypersensible.

A ce niveau, ou lors d'élicitations par des extraits de parois fongiques, et uniquement dans le cas de relations incompatibles, une production d'anions superoxyde est observée. Elle serait due à l'activation d'une NADPH-oxydase.

Les événements précoces se produisant lors d'une réaction hypersensible (dépolarisation membranaire, perte d'électrolytes et perte de la capacité de plasmolyse résultant finalement en la mort cellulaire) pourraient dépendre directement ou indirectement des ions superoxyde (Goldstein et Weissmann, 1977; Elstner, 1982; Keppler et Novacky, 1987). 
(III) L'activité de synthèse des phytoalexines a été mise en évidence dans une zone située une vingtaine de cellules au-delà des cellules mortes.

L'intervention de certains événements fondamentaux semble constante dans la plupart des réactions hypersensibles étudiées (Kiraly, 1980; Van Loon, 1982; Goodman et al., 1986; Ward, 1986). II s'agit principalement:

- de perturbations de la perméabilité membranaire;

- d'une stimulation de la production d'éthylène;

- d'un accroissement de la respiration et d'une intensification des processus oxydatifs liés à un besoin d'énergie pour la synthèse de novo de protéines;

- de stimulations de l'activité de la phénylalanine ammonia lyase (PAL), des peroxydases et des polyphénol oxydases.

Dans tous les cas, les perturbations de la perméabilité membranaire, l'accroissement de production d'éthylène et la stimulation de l'activité de la PAL sont détectés avant l'apparition de la nécrose.

Par ailleurs, des travaux récents s'appuyant sur 2 modèles très différents (tomate/Meloidogyne incognita et tabac/VMT) confirment que la génération très précoce d'anions superoxyde pourrait être une caractéristique de la réaction hypersensible (Doke et Ohashi, 1988; Zacheo et Bleve-Zacheo, 1988). Une activité superoxyde dismutase ${ }^{1}$, réduite dans les cultivars résistants et augmentée dans les cultivars sensibles, est observée par Zacheo et Bleve-Zacheo (1988).

Notons enfin que, selon certains auteurs, les réponses accompagnant une réaction hypersensible sont très semblables à celles associées aux stress, à la sénescence et aux blessures d'origine mécanique (Van Loon, 1982; Ward, 1986).

\section{Les phytoalexines}

\section{Historique et définition}

La réaction hypersensible est généralement associée à une accumulation intense de phytoalexines² (Bailey et Ingham, 1971; Bailey et Deve-

1. Les superoxyde dismutases sont des métalloenzymes qui catalysent la dismutation des anions superoxyde $\left(\mathrm{O}_{2}^{-}\right)$en $\mathrm{H}_{2} \mathrm{O}_{2}$. Elles protègent ainsi les cellules contre $\mathrm{O}_{2}-$ et empêchent la formation des autres formes actives de l'oxygène dérivées des anions superoxyde.

2. Les phytoalexines (et leur intervention dans les réactions de défense des plantes) ont fait l'objet de nombreuses synthèses ces dernières années. Le développement plus complet de certains points, seulement évoqués ici, peut être lu dans les articles de Grisebach et Ebel (1978), Stoess $(1980,1983)$, Bailey (1982a, 1982b, 1983), Darvill et Albersheim (1984), Brooks et Watson (1985), Crute et al. (1985), Kuc et Rush (1985), Ebel (1986), Keen (1986) et Smith et Banks (1986).

rall, 1971; Rahe, 1973; Bailey, 1974; Harper et al., 1987). Le terme "phytoalexine» a été créé par Müller et Borger (1940) pour désigner des substances antifongiques apparaissant dans les tissus de tubercules de pomme de terre lors de contaminations par $P$. infestans. Les auteurs observent la mort rapide des cellules végétales, au niveau du point de pénétration du parasite, accompagnée d'une réaction de défense des cellules environnantes. Les cellules ayant ainsi réagi sont "immunisées" contre de nouvelles attaques du parasite. Cette réaction de défense reste très localisée et n'entraîne jamais une prémunition de l'individu entier. Müller et Borger lient cette résistance à l'activation ou à la formation dans les cellules de l'hôte d'une substance de défense non spécifique ou phytoalexine, occasionnant la «paralysie» ou la mort du parasite. Selon ces auteurs, la résistance, bien que transmise génétiquement, n'est pas constitutive en ce sens qu'elle ne s'exprime qu'après le contact avec l'agent pathogène. Plus de 20 ans après les travaux de Müller et Borger, les premières phytoalexines (la pisatine et la phaséolline) (Fig. 1) ont été isolées puis caractérisées (Cruickshank et Perrin, 1960, 1963; Perrin et Bottomley, 1962).

Une définition de référence a été énoncée par un groupe de chercheurs (Paxton, 1981) : «Les phytoalexines sont des composés antimicrobiens

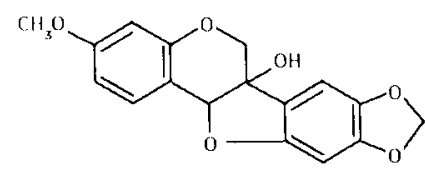

1
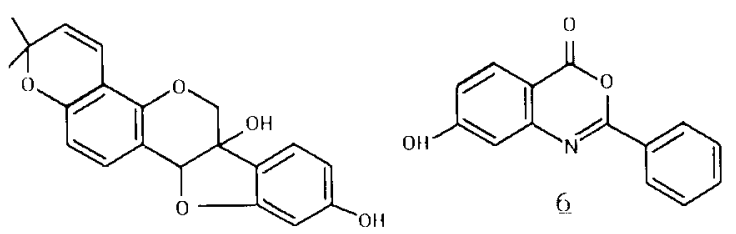

2

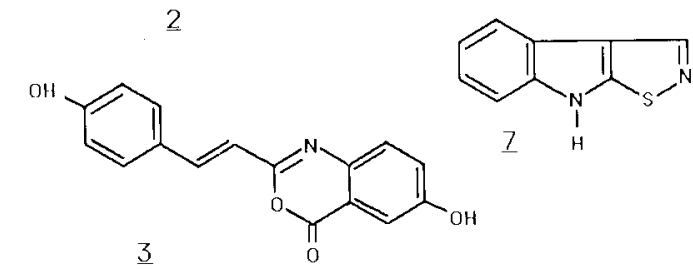

$\mathrm{H}_{3} \mathrm{C}-\mathrm{CH}_{2}-\mathrm{CH}=\mathrm{HC}-\mathrm{C} \equiv \mathrm{C}-\underset{\substack{\| \\ \mathrm{I}}}{\mathrm{C}} \mathrm{C}$

4

Fig. 1. Structure chimique de quelques phytoalexines caractéristiques. 1 : la pisatine du pois (Perrin et Bottomley, 1962), 2 : la glycéolline I du soja (Ingham, 1982), 3 : l'avénalumine I de l'avoine (Mayama et al., 1981), 4 : la wyérone de la fève (Coxon, 1982), 5 : la rishitine de la pomme de terre (Kuc, 1982), 6 : la dianthalexine de l'œillet (Ricci, 1986), 7 : la brassilexine du colza et de la moutarde brune (Devys et al., 1988). 
de faible poids moléculaire synthétisés par la plante et s'y accumulant lors d'une interaction entre cette plante et un micro-organisme."

Cette définition, qui a l'avantage d'être simple à formuler, ne s'aventure pas à prédire une éventuelle importance de ces métabolites secondaires dans la résistance de la plante. Par ailleurs, le fait que les phytoalexines puissent être synthétisées en réponse à de nombreux types de stress n'y est pas pris en compte. Enfin, Stoessl (1983) estime qu'il faut insister sur la différence entre les molécules résultant de modifications mineures (oxydations, hydroxylations...) de composés préformés et les composés réellement synthétisés selon des processus métaboliques plus complexes (phytoalexines stricto sensu).

\section{Distribution des phytoalexines dans le monde végétal}

Actuellement, plus de 200 phytoalexines ont été isolées de plantes appartenant à de nombreuses familles, principalement de l'ordre des dicotylédones (Brooks et Watson, 1985) (Fig. 1). Aucune phytoalexine n'a été trouvée chez les végétaux non vasculaires, et peu de résultats concernent les monocotylédones (Lim et al., 1968; Trivedi et Sinha, 1978; Cartwright et al., 1981; Mayama et al., 1981; Akatsuka et al., 1983; Kono et al., 1984) ou les gymnospermes (Coxon, 1982). La majeure partie des études concerne toutefois les seules légumineuses (Ingham, 1982) et solanacées (Kuc, 1982).

Les espèces d'une même famille produisent le plus souvent des phytoalexines présentant une unité de structure chimique (par exemple, les solanacées produisent principalement des sesquiterpènoïdes, les isoflavonoïdes sont caractéristiques des légumineuses, etc.) (Ingham, 1982; Smith et Banks, 1986). Aussi, Ingham et Harborne (1976) proposent-ils l'utilisation de ces métabolites secondaires pour une nouvelle approche de la systématique des végétaux supérieurs (Ingham, 1982; Stoessl, 1983). La plupart des espèces ne produisent que rarement des phytoalexines appartenant à plus de 2 ou 3 groupes de structure chimique différente et, dans une même classe de composés, les structures des phytoalexines produites sont, en général, très proches (Mansfield, 1983). Cependant, des composés présentant une même unité structurale (stilbènes par exemple) peuvent être détectés chez des espèces végétales très éloignées (Stoessl, 1983; Brooks et Watson, 1985).

\section{Propriétés chimiques et biologiques}

Les phytoalexines sont des molécules de faible poids moléculaire, généralement lipophiles (Bailey, 1982a; Van Etten et al., 1982).
Leur toxicité est couramment démontrée, non seulement vis-à-vis des champignons, mais aussi à l'encontre des bactéries, plantes supérieures et animaux (pour une revue : Smith, 1982). Selon les cas, des effets biostatiques ou biocides sont observés.

La plupart des auteurs admettent une toxicité multisite des phytoalexines et un mode d'action souvent lié à des altérations membranaires (Smith, 1982; Smith et Banks, 1986; Yoshikawa et al., 1987). II existe toutefois des exemples où une action sur la respiration cellulaire est signalée (Yoshikawa et al., 1987). Enfin, plus rarement, des effets plus ponctuels au niveau d'enzymes particulières (enzymes lytiques) (Ravisé et Kirkiacharian, 1976) de la biosynthèse des parois cellulaires, ou de la chaîne de transport d'électrons (Kaplan et al., 1980) sont observés.

\section{Elicitation et accumulation}

Les phytoalexines résultent d'un métabolisme actif nécessitant une activation génique spécifique et une synthèse de novo d'ARNm et de protéines (Yoshikawa et al., 1978b; Yoshikawa, 1983; Chappell et Hahlbrock, 1984; Ryder et al., 1984; Schmelzer et al., 1984; Cramer et al., 1985; Ryder et al., 1986; Hamdan et Dixon, 1987; Kuhn, 1988).

Elles sont, en général, absentes des plantes saines ${ }^{1}$ (Keen, 1971; Darvill et Albersheim, 1984). II s'agit de composés de stress pouvant être synthétisés et s'accumuler en réponse à des contaminations (virus, bactéries, champignons), des attaques par des insectes ou des nématodes, mais aussi à de nombreux stimuli abiotiques (éthylène, froid, UV, fongicides, sels métalliques, détergents, stress dus à l'environnement) ou à des élicitations biotiques (composantes de parois bactériennes, fongiques ou végétales, enzymes microbiennes, etc.); en revanche, une blessure ne semble pas toujours suffisante pour induire cette synthèse (Kuc, 1976; Lisker et Kuc, 1977; Hargreaves et Bailey, 1978; Stuessl, 1980; Moesta et Grisebach, 1981a; Bostock et al., 1982; Yoshikawa, 1983; Darvill et Albersheim, 1984; De Wit, 1986; Ward, 1986).

Les modalités d'action des éliciteurs abiotiques pouvant conduire à une accumulation de phytoalexines restent controversées. Certains

1. Cette absence dans les plantes «saines» pourrait n'être due qu'à l'insuffisance des techniques de détection actuelies. A l'opposé, lorsque des phytoalexines sont détectées dans des plantes «saines", il est toujours difficile de savoir s'il s'agit réellement de composés constitutifs ou si cette présence est la résultante des nombreux stress qui accompagnent la culture des plantes. La notion de plante saine se rapporte finalement à un individu idéal n'ayant subi aucun stress environnemental ou biotique. 
auteurs (Bailey, 1983) considèrent que la mort cellulaire est à l'origine de tous les phénomènes d'élicitation (Fig. 2) et estiment que les éliciteurs abiotiques agissent comme les parasites. Dans ce cas, la libération d'éliciteurs endogènes, lors d'une dégradation importante des parois cellulaires, déclencherait les mécanismes de défense (Moesta et Grisebach, 1981a). Dans cette optique, Loschke et al. (1983) montrent qu'une attaque du pois par Fusarium solani ou par divers éliciteurs abiotiques induit la synthèse de novo d'un grand nombre de protéines identiques. Pour Yoshikawa (1978), les éliciteurs abiotiques agiraient surtout en inhibant le métabolisme des phytoalexines. Selon cet auteur, la synthèse de ces métabolites est stimulée par certains éliciteurs biotiques (ou la contamination), alors que les éliciteurs abiotiques ne stimulent pas leur synthèse, mais inhibent leur dégradation. Yoshikawa (1978) en conclut que «les effets régulateurs primaires des éliciteurs biotiques et abiotiques sont nettement différents". Curieusement, en utilisant la même espèce (Glycine max), Moesta et Grisebach (1981a) en arrivent à des conclusions radicalement opposées et déclarent que «l'accumulation de glycéolline dans les cotylédons de soja est principalement, sinon exclusivement, contrôlée par le taux de synthèse de la phytoalexine", les effets des éliciteurs biotiques et abiotiques restant très similaires.

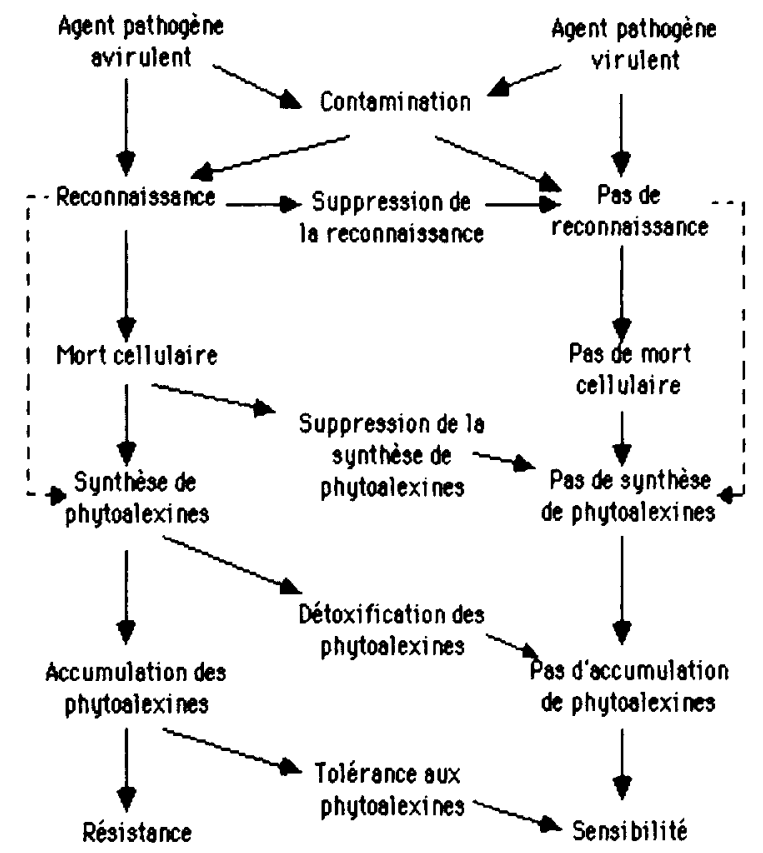

Fig. 2. Facteurs pouvant affecter l'accumulation des phytoalexines et la résistance des plantes lors d'une attaque parasitaire (d'après Mansfield, 1982). L'importance de la mort cellulaire en tant que signal permettant de déclencher les synthèses de phytoalexines restant une hypothèse, l'auteur envisage la possibilité de ne pas prendre en compte cette étape (flèches pointillées).
Les éliciteurs abiotiques sont généralement préférés aux contaminations pour obtenir de grandes quantités de phytoalexines (Strange, 1987; Rouxel, 1988). Ils sont aussi particulièrement intéressants pour comparer les capacités intrinsèques de production de différents cultivars sans tenir compte du parasite (Rouxel, 1988). Ce procédé permet en particulier d'éviter une éventuelle dégradation des phytoalexines par le parasite, ainsi que l'activité de suppresseurs des réactions de la plante (Strange, 1987; Rouxel, 1988).

Enfin, quand une plante produit plusieurs phytoalexines, la composition du mélange obtenu peut dépendre de l'agent inducteur, de l'organe considéré, des conditions extérieures et de la durée du traitement ou de l'interaction (Sutton et Deverall, 1984; Goossens et al., 1987).

\section{Corrélation avec la réaction hypersensible et la} résistance

Toutes les plantes, qu'elles soient sensibles ou résistantes, semblent posséder les gènes nécessaires à la production de phytoalexines (Keen, 1971).

Lors d'une attaque parasitaire, la réponse d'une plante résistante peut être extrêmement rapide, puisque Hahn et al. (1985) détectent les premières traces de glycéolline dans des racines de soja $2 \mathrm{~h}$ après la contamination. L'accumulation est très retardée et/ou moins intense chez les plantes sensibles à un parasite et ne présentant pas (ou peu) de réaction hypersensible à ce dernier (Bailey et Deverall, 1971; Keen, 1971; Varns et al., 1971; Rahe, 1973; Yoshikawa et al., 1978a; Mayama et al., 1981; Moesta et Grisebach, 1981b; Doke, 1982; Hahn et al., 1985; Bhattacharyya et Ward, 1987; Rouxel, 1988; Rouxel et al., 1989a). La résistance à un parasite ne serait donc pas en corrélation avec une capacité de synthèse de type "tout ou rien", mais avec la vitesse à laquelle les phytoalexines sont synthétisées et s'accumulent (Kuc, 1976; Kuc et Rush, 1985; Ryder et al., 1986; Esnault et al., 1987; Rouxel, 1988).

Par ailleurs, une relation entre cellules mortes et cellules vivantes semble nécessaire à l'accumulation de phytoalexines (Hargreaves et Bailey, 1978; Hargreaves, 1979; Bailey, 1982a, 1982b) : ces métabolites sont concentrés dans les cellules mortes (réaction hypersensible) ou à la limite des lésions (nécrose bloquante tardive ou sensibilité), mais ne sont pas (ou peu) présents dans les tissus sains environnants (Bailey et Deverall, 1971; Rahe, 1973; Rathmell, 1973; Bailey, 1982b; Moesta et al., 1982). Ce fait est lié par Hargreaves et Bailey (1978) à la capacité qu'ont 
les cellules végétales vivantes à métaboliser ou à adsorber les phytoalexines (Yoshikawa et al., 1979; Bailey, 1982a; Sakai et al., 1982; Bhattacharyya et Ward, 1987).

\section{Implications de la réaction hypersensible et des phytoalexines dans la résistance}

\section{La réaction hypersensible et la mort cellulaire associée}

A l'origine, la nécrose cellulaire associée à la réaction hypersensible paraissait suffisante pour expliquer la limitation de croissance d'un parasite biotrophe, ne pouvant plus tirer sa subsistance de cellules mortes (Marryat, 1907; Müller, 1959). Mais l'observation que la réaction survient aussi en réponse à des infections par des parasites hémibiotrophes, voire nécrotrophes, oblige à reconsidérer cette hypothèse.

Van der Plank (1982), Kiraly et al. (1972) et Goodman et al. (1986) estiment que la réaction hypersensible survient après l'inhibition de croissance du parasite, mais bien avant une invasion secondaire. En effet, certains auteurs montrent que la mort de champignons compatibles dans la plante permet d'induire la réaction hypersensible et l'accumulation de phytoalexines (Kiraly et al., 1972; Ersek et al., 1973; Hevesi et Mashaal, 1975; Börner et al., 1983). Kiraly (1980) en conclut que «l'hypersensibilité et les phytoalexines constitueraient une résistance préformée face aux infections secondaires». Dans ce cas, les auteurs envisagent l'intervention de mécanismes encore inconnus pour stopper la croissance mycélienne et, plus tardivement, la libération par le parasite inhibé d'cendotoxines" induisant la réaction hypersensible.

Plusieurs observations vont à l'encontre de cette analyse.

La présence d'éliciteurs non spécifiques dans les parois bactériennes et fongiques, capables d'induire une réaction hypersensible sur des cultivars compatibles (Sato et al., 1968; Varns et Kuc, 1971; Keen et al., 1981; Darvill et Albersheim, 1984), a permis d'expliquer pourquoi la mort du parasite dans la plante (et donc la dégradation de ses parois) était à l'origine d'une telle réaction. Certains auteurs ont alors émis l'hypothèse que la compatibilité est un phénomène actif, lié à l'activité de suppresseurs de la reconnaissance ou, plus tardivement, de suppresseurs de synthèses chez l'hôte (Fig. 2), empêchant la plante de réagir (Ward, 1986). On comprend ainsi que la dégradation de tels suppresseurs constitutifs favorise l'accessibilité d'éliciteurs non spécifiques. De même, si le parasite nécessite une "adaptation aux tissus de l'hôte" avant d'expri- mer son potentiel suppresseur (Varns et Kuc, 1971), ou si une synthèse active de composés ayant une telle activité (pathotoxines par exemple) est requise, on comprend que la mort de l'agent pathogène, empêchant l'expression de ce potentiel, conduise à une réaction hypersensible.

Par ailleurs, dans le modèle pomme de terre/ $P$. infestans, la mort des cellules de l'hôte (mais non le phénomène nécrotique macroscopiquement visible, plus tardif) précède de $7 \mathrm{~h}$ au moins l'inhibition de croissance du parasite (Clarke, 1983). La même séquence d'événements (mort de quelques cellules de l'hôte/accumulation de phytoalexines/mort du parasite) a été montrée pour la relation entre Phaseolus vulgaris et $\mathrm{Col}$ letotrichum lindemuthianum (Bailey et al., 1980; Bailey, 1982b). En accord avec ces données, et bien que des exceptions puissent être décrites ${ }^{1}$ (Harder et al., 1979b), la plupart des études montre que les cellules végétales meurent peu après le contact avec le parasite et que le développement de l'hyphe est inhibé ultérieurement (Sato et al., 1968; Skipp et Deverall, 1972; Skipp et Samborski, 1974; Maclean et al., 1974; Sato et Tomiyama, 1976; Rossall et al., 1980; Ingram, 1982; Bailey, 1983; Woods et al., 1988).

Une autre objection à l'importance de la réaction hypersensible dans la résistance provient d'auteurs ayant observé que cette réaction ne provoque pas toujours la mort du parasite ou que le parasite réussit à se développer au-delà de la nécrose réactionnelle avant d'être (ou non) inhibé (Chakravarti, 1966; Mayama et al., 1975; Bailey et Rowell, 1980; Gousseau et Deverall, 1987; Johal et Rahe, 1988). De même, certains auteurs n'ont pas trouvé de corrélation entre la nécrose et la présence ou l'étendue du développement du parasite (Brown et al., 1966; Ogle et Brown, 1971; Harder et al., 1979a, 1979b; Rohringer et al., 1979).

Les phytoalexines qui s'accumulent lors d'une réaction hypersensible sont souvent considérées comme des molécules fongistatiques plutôt que fongitoxiques (Smith, 1982). De plus, certains parasites sont capables de détoxifier ces métabolites (voir paragraphe suivant "Synthèse et accumulation des phytoalexines»). Cela expliquerait l'adaptation à un environnement toxique (lors d'une augmentation progressive de la concentration en phytoalexines) observée chez certains parasites (Bailey, 1982b).

1. En ce qui concerne la comparaison spatio-temporelle des événements, il est intéressant de noter la critique de Meyer et Heath (1988), selon laquelle la première phase de la mort des cellules végétales, c'est-à-dire l'arrêt du flux cytoplasmique, n'est pas détectable lors d'observations au microscope électronique. 
De façon plus anecdotique, Gracen (1982) décrit une réaction hypersensible "constitutive", dans les mutants Les 2 de maïs. Cette réaction apparaît à certains stades du développement de la plante, sans qu'il s'agisse d'une réponse à une agression parasitaire.

Crute et al. (1985) concluent de ces observations contradictoires qu'il n'existe pas une vérité unique, et que, en fonction des auteurs et/ou des relations hôte-agent pathogène considérées, la réaction hypersensible et la mort cellulaire peuvent être appréhendées selon diverses éventualités ne s'excluant pas forcément les unes les autres:

- la réaction et la mort cellulaire précèdent l'inhibition de croissance du parasite et contribuent directement à la résistance;

- la réaction précède l'inhibition de croissance du parasite, mais la mort cellulaire n'est pas directement responsable de la résistance;

- la réaction est induite par des métabolites venant du parasite, dont le développement a été inhibé par d'autres mécanismes;

- la réaction résulte d'une condition de stress non spécifique et ne contribue pas à la résistance (on pourrait ajouter : la réaction résulte d'une condition de stress non spécifique et contribue à la résistance).

Ingram (1982) suggère qu'une meilleure définition structurale et biochimique des termes «hypersensibilité» et «limitation de la croissance fongique" permettrait sans doute de mieux comprendre l'importance de la «mort cellulaire accélérée» dans la résistance.

\section{Synthèse et accumulation des phytoalexines}

Keen (1982) cite 16 systèmes hôte-parasite dans lesquels différents auteurs ont montré une accumulation plus importante de phytoalexines lors de relations incompatibles que lors de relations compatibles.

L'hypothèse d'un rôle des phytoalexines en tant que mécanisme de défense vis-à-vis des agents pathogènes est encore renforcée par diverses observations:

- l'ubiquité de ce type de synthèse en réponse à un stress (au moins chez les dicotylédones);

- les propriétés antibiotiques des phytoalexines;

- leur absence dans les plantes saines et leur synthèse active;

- la forte corrélation existant entre la limitation de la croissance de l'agent pathogène dans les lésions hypersensibles nécrotiques et l'accumulation rapide de quantités toxiques de phytoalexines précédant cette restriction de croissance
(Bailey et Deverall, 1971; Bailey, 1974; Yoshikawa et al., 1978a; Bailey et al., 1980; Mayama et al., 1981; Doke, 1982; Mayama et Tani, 1982; Sakai et al., 1982; Crute et al., 1985; Hahn et al., 1985);

- enfin, l'inversion de compatibilité observée lorsque des inhibiteurs suppriment la synthèse de phytoalexines chez des plantes résistantes (Yoshikawa et al., 1978a, 1978b; Keen et al., 1981; Mayama et al., 1982; Moesta et Grisebach, 1982; Long et al., 1985; Rouxel, 1988).

Si les phytoalexines sont réellement importantes pour la défense de la plante, l'agent pathogène doit éviter cette barrière induite soit en empêchant la plante de détecter sa présence, soit en supprimant la synthèse de phytoalexines, soit enfin en détoxifiant et/ou en tolérant ces métabolites (Mansfield, 1982) (Fig. 2).

Différents composés supprimant la reconnaissance, et donc la réaction potentielle de l'hôte, sont décrits par divers auteurs (Doke, 1975; Garas et al., 1979; Doke et Tomiyama, 1980; Oku et al., 1980; Heath, 1982; Ziegler et Pontzen, 1982; Oku et al., 1987). Par ailleurs, quelques pathotoxines non spécifiques, telles que la phaséotoxine de Pseudomonas phaseicola, la brefeldine A d'Alternaria carthami, ou la sirodesmine PL de Leptosphaeria maculans, en agissant sur le métabolisme de la plante, inhibent, parfois de façon minime, l'accumulation de phytoalexines en réponse à une contamination ou à un stress abiotique (Gnanamanickam et Patil, 1977; Tietjen et Matern, 1984; Rouxel et al., 1988; Rouxel, 1988). Oku et al. (1987) estiment que la synthèse de phytoalexines est plus faible lors de relations compatibles que lors de relations incompatibles, en raison de mécanismes de suppression de la reconnaissance ou des synthèses.

L'exemple le mieux documenté d'une agressivité liée à la capacité de dégrader une phytoalexine concerne le couple pois/Nectria haematococca. Van Etten et al. (1980) et Tegtmeier et Van Etten (1982) testent 59 isolats du parasite, puis engagent une étude génétique en croisant entre eux les différents isolats. Ils montrent alors que tous les isolats modérément ou fortement agressifs ont la capacité de déméthyler la pisatine et/ou de la tolérer. Aucun de ces isolats n'est sensible à la phytoalexine. A l'opposé, tous les isolats ne possédant pas cette capacité sont sensibles à la phytoalexine et présentent une faible agressivité vis-à-vis de la plante.

Une meilleure tolérance de l'agent pathogène aux phytoalexines ou une capacité à les dégrader est observée dans plusieurs autres cas (Cruickshank, 1962; Mansfield et Widdowson, 
1973; Van Etten, 1973; Bailey, 1974; Pueppke et Van Etten, 1974; Macfoy et Smith, 1979; Kaplan et al., 1980; Rossall et al., 1980; Van Etten et al., 1982; Smith et al., 1984; Lucy et al., 1988).

Toutefois, il existe au moins un contreexemple. Selon les auteurs, Aphanomyces euteiches est le parasite du pois le plus sensible à la pisatine in vitro (et il est incapable de la dégrader). Pourtant, sa croissance n'est pas ralentie dans des lésions végétales contenant 8 à 20 fois plus de pisatine qu'il ne peut en supporter in vitro (Van Etten, 1973; Pueppke et Van Etten, $1974,1976)$. Sweigard et Van Etten (1984) montrent cependant que des lipides fortement polaires, extraits du pois, diminuent la sensibilité du parasite à la pisatine, ainsi qu'à d'autres phytoalexines.

\section{Réaction hypersensible et accumulation de phy- toalexines}

Réaction hypersensible et accumulation intense de phytoalexines étant 2 phénomènes étroitement associés, plusieurs équipes ont tenté de les dissocier de façon à évaluer leur part respective dans la résistance.

L'utilisation d'inhibiteurs de synthèse des acides aminés aromatiques (glyphosate) ou d'inhibiteurs compétitifs de la PAL (acide $\alpha$-aminooxyacétique (AOA) et acide $\alpha$-amino-oxy- $\beta$-phénylpropionique (AOPP)) permet, dans plusieurs modèles, cette dissociation. Dans le cas du couple Phaseolus vulgaris/Colletotrichum lindemuthianum, l'utilisation du glyphosate conduit Johal et Rahe (1988) à conclure que la réponse la plus importante de la plante est la synthèse de phytoalexines. Elle serait responsable de la restriction du parasite dans les cellules mortes. Sato et al. (1971), Mayama et al. (1982) en utilisant l'AOA, et Moesta et Grisebach (1982) en utilisant I'AOPP arrivent aux mêmes conclusions dans le cas des relations entre la pomme de terre et $P$. infestans, entre l'avoine et Puccinia coronata f. sp. avenae, et entre le soja et Phytophthora megasperma f. sp. glycinea, respectivement.

Comme le propose Ricci (1986), la mort cellulaire, dans un certain nombre de cas tout au moins, "semble jouer un rôle essentiel dans le processus d'élicitation. On peut l'envisager comme un phénomène intégrateur par lequel la plante traduit une grande diversité d'agressions en un message unique déclenchant la panoplie des mécanismes de défense" (ct. aussi : Bailey, 1982a, 1983; Ward, 1986).

\section{Discussion}

Pour certaines relations hôte-parasite, quelques travaux montrent de façon non équivoque que les phytoalexines jouent un rôle central, voire exclusif, dans la résistance aux agents pathogènes (voir, en particulier, Van Etten et al. (1980) et Tegtmeier et Van Etten (1982) pour le couple pois/N. haematococca).

Cependant, ces études restent minoritaires et, bien que les phytoalexines soient un marqueur indiscutable de la réaction hypersensible, leur intervention en tant qu'effecteur de la résistance active, ou leur part dans la résistance hypersensible, est souvent controversée.

II convient de rappeler à ce propos que la définition de Paxton (1981) ne mentionne pas une éventuelle intervention des phytoalexines dans la résistance.

Cette controverse est alimentée en premier lieu par le fait qu'aucune phytoalexine n'a été mise en évidence dans plusieurs relations hôteparasite (Coxon, 1982; Mansfield, 1982; Reisener et al., 1986). L'ubiquité de leur synthèse reste donc toute relative, bien que de tels métabolites secondaires aient été mis en évidence dans toutes les dicotylédones où ils ont été recherchés, à l'exception notable des cucurbitacées.

Par ailleurs, pour certaines interactions, l'accumulation intense de phytoalexines n'est pas en corrélation avec la résistance à l'agent pathogène, sans qu'une meilleure tolérance, ou une détoxification du composé antimicrobien par le parasite, puisse être mise en évidence. Tel est le cas de l'interaction colza/Leptosphaeria maculans (Dahiya et Rimmer, 1988) ou du couple piment/Phytophthora capsici (Molot et al., 1985). Dans le premier cas, une accumulation intense de méthoxybrassinine et de cyclobrassinine accompagne une créaction hypersensible inefficace" de la plante vis-à-vis du champignon (Dahiya et Rimmer, 1988; Rouxel, 1988). Dans le second cas, Ricci (1986) souligne que le capsidiol ufonctionne comme une phytoalexine" vis-à-vis de certains agents pathogènes mais non de $P$. capsici. La réponse des plantes aux agressions parasitaires est constituée d'un ensemble de mécanismes peu adaptés et non spécifiques en ce qui concerne leur induction et leur toxicité (Kuc et Rush, 1985). En effet, la gamme des réponses possibles d'un cultivar reste limitée, dès l'origine, par ses capacités génétiques. En particulier, si le "cocktail» de phytoalexines produites peut subir quelques variations en fonction de l'agent pathogène présent (variations portant surtout sur la part respective de chaque phytoalexine dans l'ensemble), il reste cependant relativement figé et incapable de s'adapter à de subtiles modifications dans le pouvoir pathogène du parasite.

II faut enfin insister sur le fait que l'accumulation intense de phytoalexines n'est que l'une des 
réponses associées à la réaction hypersensible (Bell, 1980, 1981; Goodman et al., 1986; Heath, 1986). Différentes barrières structurales ou chimiques (lignification, accumulation de glycoprotéines riches en hydroxyproline, inhibiteurs d'enzymes, enzymes lytiques...) pourraient aussi intervenir en tant que déterminants de l'incompatibilité (Touzé et Esquerré-Tugaye, 1982).

Cette analyse conduit à se demander si la relative facilité de l'étude des phytoalexines par rapport à d'autres mécanismes n'a pas faussé l'étude des réactions de défense des plantes (parmi lesquelles la réaction hypersensible), en la focalisant sur un phénomène "spectaculaire" et simple à appréhender, au détriment, peut-être, de manifestations tout aussi importantes mais moins faciles à étudier, ou dont l'intervention dans la résistance serait moins aisée à concevoir.

Notons pour terminer que le dosage des phytoalexines est généralement effectué dans le broyat d'une quantité plus ou moins importante de matériel végétal. Une telle méthodologie est très insuffisante pour donner une réelle idée des sites et de la cinétique d'accumulation ponctuelle de ces métabolites. Dans les années à venir, le développement de techniques de dosage/visualisation in situ (voir, par exemple, Moesta et al., 1982) permettra sans doute de savoir s'il y a "contact" entre les métabolites toxiques et le parasite, ou si les sites d'accumulation préférentiels des phytoalexines sont inaccessibles au parasite. Ces techniques permettront aussi de quantifier les concentrations de phytoalexines auxquelles sont confrontés les agents pathogènes in vivo et assureront une meilleure compréhension de l'intervention des phytoalexines dans les phénomènes de résistance.

\section{Conclusion : intérêts de l'étude des phytoa- lexines}

L'étude des phytoalexines permet, tout d'abord, une meilleure connaissance de la relation hôteparasite. Leur accumulation en grandes quantités étant généralement associée à une réaction hypersensible, les phytoalexines sont surtout utilisées pour tenter de quantifier cette réaction. Ses caractéristiques résultent en effet de nombreux mécanismes biochimiques conduisant à une nécrose, dont on ne peut estimer l'importance que "visuellement" (nombre de cellules touchées, rapidité de la réponse, etc.). Pour une meilleure compréhension des phénomènes de reconnaissance et de spécificité parasitaire, cette quantification trouve une application dans l'étude des éliciteurs isolés de parois microbiennes ou d'un filtrat de culture.
L'étude des phytoalexines permet aussi une meilleure connaissance de la physiologie et de la biochimie de la plante (Bailey, 1982a). Grisebach et Ebel (1978) insistent sur l'apport de l'étude de la biosynthèse des phytoalexines pour une compréhension du contrôle de l'expression des gènes des cellules végétales. Par ailleurs, une action physiologique de certaines phytoalexines (glycéolline, pisatine, rishitine et phaséolline) est décrite par Yoshikawa et al. (1987). Les auteurs observent en effet que ces métabolites agissent, à très faibles concentrations, en synergie avec l'acide $\beta$-indolyl-acétique (AIA) pour stimuler la différenciation (mais non la croissance) de racines, à la base sectionnée d'hypocotyles de «faux soja» (Vigna radiata).

L'utilisation des phytoalexines pour une nouvelle approche de la systématique des végétaux supérieurs a déjà été évoquée ici.

II a aussi été envisagé de les utiliser comme modèles structuraux pour l'obtention de nouveaux fongicides, mais leur faible fongitoxicité, associée à leur faible translocation dans les plantes et leur manque de spécificité, n'a pas encore permis de déboucher sur des produits commercialisables (Mansfield et Bailey, 1982). Leur phytotoxicité (et toxicité animale) en fait par ailleurs des candidats peu attrayants dans cette optique. De même, aucune application pharmacologique n'a été rapportée.

Certains auteurs (Strange, 1987) envisagent de sélectionner des plantes plus résistantes aux parasites sur leur capacité de synthèse de phytoalexines en réponse à un stress abiotique.

Enfin, leur utilisation en tant que marqueur précoce de la résistance, lors de croisements interspécifiques entre Brassica sensibles et résistantes à Leptosphaeria maculans, est proposée par Rouxel (1988) et Rouxel et al. (1989b). Elle suppose une technique fiable d'élicitation à des stades précoces de développement des plantes (voire sur cultures in vitro), ainsi que des techniques précises de dosage permettant de différencier la capacité d'accumulation des plantes sensibles de celle des plantes résistantes.

\section{Remerciements}

Je tiens à remercier G. Bompeix (Pathologie végétale, université de Paris-VI) et $\mathrm{C}$. Descoins (Phytopharmacie, INRA, Versailles), qui m'ont incité à publier cette revue; $M$. Ponchet (Pathologie végétale, INRA, Antibes) pour sa lecture critique de cet article et ses suggestions; J.F. Bousquet et A. Kollmann (Pathologie végétale, INRA, Versailles) pour de nombreuses et fructueuses discussions; $G$. Touraud (Pathologie végétale, INRA, Versailles) pour sa révision du manuscrit; et I. Fiala et G. Lacaze (Pathologie végétale, INRA, 
Versailles) pour leur aide dans la constitution de ma bibliographie.

\section{Références}

Akatsuka T., Kodama O., Kato H., Kono Y. \& Takeuchi S. (1983) 3-hydroxy-7-oxo-sandaracopimaradiene (oryzalexin A), a new phytoalexin isolated from rice blast leaves. Agric. Biol. Chem. 47, 445.447

Asher M.J.C. \& Thomas C.E. (1983) The expression of partial resistance to Erysiphe graminis in spring barley. Plant Pathol. 32, 79-89

Bailey J.A. (1974) The relationship between symptom expression and phytoalexin concentration in hypocotyls of Phaseolus vulgaris infected with Colletotrichum lindemuthianum. Physiol. Plant Pathol. 4, 477-488

Bailey J.A. (1982a) Mechanisms of phytoalexin accumulation. In : Phytoalexins (Bailey J.A. \& Mansfield J.W., eds). Blackie \& Son Ltd., Glasgow \& London, pp. 289-318

Bailey J.A. (1982b) Physiological and biochemical events associated with expression of resistance to disease. In : Active Defense Mechanisms in Plants (Wood R.K.S., ed.). NATO Advanced Studies, Series A, Plenum Press, New York \& London, pp. 39-65

Bailey J.A. (1983) Biological perspectives of hostpathogen interactions. In : The Dynamics of Host Defense (Bailey J.A. \& Deverall B.J., eds). Academic Press, Sydney, pp. 1-32

Bailey J.A. \& Ingham J.L. (1971) Phaseollin accumulation in bean (Phaseolus vulgaris) in response to infection by tobacco necrosis virus and the rust Uromyces appendiculatus. Physiol. Plant Pathol. 1, 451-456

Bailey J.A. \& Deverall B.J. (1971) Formation and activity of phaseollin in the interaction between bean hypocotyls (Phaseolus vulgaris) and physiological races of Colletotrichum lindemuthianum. Physiol. Plant Pathol. 1, 435-449

Bailey J.A. \& Rowell P.M. (1980) Viability of Colletotrichum lindemuthianum in hypersensitive cells of Phaseolus vulgaris. Physiol. Plant Pathol. 17, 341-345

Bailey J.A., Rowell P.M. \& Arnold G.M. (1980) The temporal relationship between host cell death, phytoalexin accumulation and fungal inhibition during hypersensitive reactions of Phaseolus vulgaris to Colletotrichum lindemuthianum. Physiol, Plant Pathol. 17, 329-339

Bell A.A. (1980) The time sequence of defense. In : Plant Disease. Vol. 5. How Plants Defend Themselves (Horsfall J.G. \& Cowling E.B., eds). Academic Press, New York, pp. 53-73

Bell A.A. (1981) Biochemical mechanisms of disease resistance. Ann. Rev. Plant Physiol. 32, 21-81

Bhattacharyya M.K. \& Ward E.W.B. (1987) Biosynthesis and metabolism of glyceollin I in soybean hypocotyls following wounding or inoculation with Phytophthora megasperma f. sp. glycinea. Physiol. Mol. Plant Pathol. 31, 387-405

Bompeix G., Fettouche F. \& Saindrenan P. (1981) Mode d'action du phosétyl Al. Phytiatr.-Phytopharm. Rev. Fr. Med. Pharm. Veg. 30, 257-272

Börner H., Schatz G. \& Grisebach H. (1983) Influence of the systemic fungicide metalaxyl on glyceollin accu- mulation in soybean infected with Phytophthora megasperma f. sp. glycinea. Physiol. Plant Pathol. 23, 145-152

Bostock R.M., Laine R.A. \& Kuc J.A. (1982) Factors affecting the elicitation of sesquiterpenoid phytoalexin accumulation by eicosapentaenoic and arachidonic acids in potato. Plant Physiol. 70, 1417-1424

Brooks C.J.W. \& Watson D.G. (1985) Phytoalexins. Nat. Prod. Rep. 427-459

Brown J.F., Shipton W.A. \& White N.H. (1966) The relationship between hypersensitive tissue and resistance in wheat seedlings infected with Puccinia graminis tritici. Ann. Appl. Biol. 58, 279-290

Cartwright D.W., Langcake P. \& Ride J.P. (1980) Phytoalexin production in rice and its enhancement by a dichlorocyclopropane fungicide. Physiol. Plant Pathol. $17,259-267$

Cartwright D.W., Langcake P., Pryce R.J., Leworthy D.P. \& Ride J.P. (1981) Isolation and characterization of two phytoalexins from rice as momilactones $A$ and B. Phytochemistry 20,535-537

Chakravarti B.P. (1966) Attempts to alter infection processes and aggressiveness of Puccinia graminis var. tritici. Phytopathology 56, 223-229

Chappell J. \& Hahlbrock K. (1984) Transcription of plant defence genes in response to UV light or fungal elicitor. Nature 311, 76-78

Clarke D.D. (1983) Potato late blight: a case study. In: Biochemical Plant Pathology (Callow J.A., ed.). John Wiley \& Sons, Chichester, pp. 3-17

Coffey M.D. (1983) Flax rust: a case study. In: Biochemical Plant Pathology (Callow J.A., ed.). John Wiley \& Sons, Chichester, pp. 31-43

Coffey M.D. \& Wilson U.E. (1983) An ultrastructural study of the late-blight fungus Phytophthora infestans and its interaction with the foliage of two potato cultivars possessing different levels of general (field) resistance. Can. J. Bot. 61, 2669-2685

Coxon D.T. (1982) Phytoalexins from other families. In: Phytoalexins (Bailey J.A. \& Mansfield J.W., eds). Blackie \& Son Ltd, Glasgow \& London, pp. 106-132

Cramer C.L., Ryder T.B., Bell J.N. \& Lamb C.J. (1985) Rapid switching of plant gene expression induced by fungal elicitor. Science 227, 1240-1243

Cruickshank I.A.M. (1962) Studies on phytoalexins. IV. The antimicrobial spectrum of pisatin. Aust. J. Biol. Sci. 15, 147-159

Cruickshank I.A.M. \& Perrin D.R. (1960) Isolation of a phytoalexin from Pisum sativum L. Nature 187, 799800

Cruickshank I.A.M. \& Perrin D.R. (1963) Phytoalexins of the Leguminosae. Phaseollin from Phaseolus vulgaris. Life Sci. 2, 680-682

Crute I.R. \& Dickinson C.H. (1976) The behaviour of Bremia lactucae on cultivars of Lactuca sativa and on other composites. Ann. Appl. Biol. 82, 433-450

Crute I.R., De Wit P.J.G.M. \& Wade M. (1985) Mechanims by which genetically controlled resistance and virulence influence host colonization by fungal and bacterial parasite. In: Mechanims of Resistance to Plant Diseases (Fraser R.S.S., ed.). Martinus Nijhoff/Dr W. Junk Publishers, Dordrecht, pp. 197-309 Dahiya J.S. \& Rimmer S.R. (1988) Phytoalexin accumulation in tissues of Brassica napus inoculated with Leptosphaeria maculans. Phytochemistry 27, 31053107 
Darvill A.G. \& Albersheim P. (1984) Phytoalexins and their elicitors. A defense against microbial infection in plants. Annu. Rev. Plant Physiol. 35, 243-275

Day P.R. (1974) Genetics of Host-Parasite Interaction (Kelman A. \& Sequeira L., eds). W.H. Freeman \& Co., San Francisco

Devys M., Barbier M., Loiselet I., Rouxel T., Sarniguet A., Kollmann A. \& Bousquet J.F. (1988) Brassilexin, a novel sulphur-containing phytoalexin from Brassica juncea L. (Cruciferae). Tetrahedron Lett. 29, 6447 6448

De Wit P.J.G.M. (1977) A light and scanning-electron microscopic study of infection of tomato plants by virulent and avirulent races of Cladosporium fulvum Neth. J. Plant Pathol. 83, 109-122

De Wit P.J.G.M. (1986) Elicitation of active resistance mechanisms. In: Biology and Molecular Biology of Plant-Pathogen Interactions (Bailey J.A., ed.). NATO ASI Series, Vol. 1, Springer-Verlag, Berlin, pp. 149-169

Doke N. (1975) Prevention of the hypersensitive reaction of potato cells to infection with an incompatible race of Phytophthora infestans by constituents of the zoospores. Physiol. Plant Pathol. 7, 1-7

Doke N. (1982) A further study on the role of hypersensitivity in resistance of potato cultivars to infection by an incompatible race of Phytophthora infestans. Physiol. Plant Pathol. 21, 85-95

Doke N. \& Tomiyama K. (1980) Suppression of the hypersensitive response of potato tuber protoplasts to hyphal wall components by water soluble glucans isolated from Phytophthora infestans. Physiol. Plant Pathol. 16, 177-186

Doke N., Chai H.B. \& Kawaguchi A. (1987) Biochemical basis of triggering and suppression of hypersensitive cell response. In: Molecular Determinants of Plant Diseases (Nishimura S., Vance C.P. \& Doke N., eds). Jpn Scient. Soc. Press, Tokyo, Springer-Verlag, Berlin, pp. 235-249

Doke N. \& Ohashi Y. (1988) Involvement of an $\mathrm{O}_{2}-$ generating system in the induction of necrotic lesions on tobacco leaves infected with tobacco mosaic virus. Physiol. Mol. Plant. Pathol. 32, 163-175

Ebel J. (1986) Phytoalexin synthesis: the biochemical analysis of the induction process. Annu. Rev. Phytopathol. 24, 235-264

Ellingboe A.H. (1972) Genetics and physiology of primary infection by Erysiphe graminis. Phytopathology 62, 401-406

Elstner E.F. (1982) Oxygen activation and oxygen toxicity. Annu. Rev. Plant Physiol. 33, 73-96

Érsek T., Barna B. \& Kiraly Z. (1973) Hypersensitivity and the resistance of potato tuber tissues to Phytophthora infestans. Acta Phytopathol. Acad. Sci. Hung. 8, 3-12

Esnault R., Chibbar R.N., Lee D., Van Huystee R.B. \& Ward E.W.B. (1987) Early differences in production of mRNAs for phenylalanine ammonia-lyase and chalcone synthase in resistant and susceptible cultivars of soybean inoculated with Phytophthora megasperma f. sp. glycinea. Physiol. Mol. Plant Pathol. 30, 293-297

Farrara B.F., llott T.W. \& Michelmore R.W. (1987) Genetic analysis of factors for resistance to downy mildew (Bremia lactucae) in species of lettuce (Lactuca sativa and L. serriola). Plant Pathol. 36, 499-514

Flor H.H. (1971) Current status of the gene-for-gene concept. Annu. Rev. Phytopathol. 9, 275-296
Fuchs W.H. (1976) History of physiological plant pathology. In: Physiological Plant Pathology, Vol. 4 (Heitefuss R. \& Williams P.H., eds). Springer-Verlag, Berlin, pp. 1-26

Garas N.A., Doke N. \& Kuc J. (1979) Suppression of the hypersensitive reaction in potato tubers by mycelial components from Phytophthora infestans. Physiol. Plant Pathol. 15, 117-126

Gees R. \& Hohl H.R. (1988) Cytological comparison of specific $(R 3)$ and general resistance to late blight in potato leaf tissue. Phytopathology 78, 350-357

Gnanamanickam S.S. \& Patil S.S. (1977) Phaseotoxin suppresses bacterially induced hypersensitive reaction and phytoalexin synthesis in bean cultivars. Physiol. Plant Pathol. 10, 169-179

Goldstein I.M. \& Weissmann G. (1977) Effects of the generation of superoxide anion on permeability of liposomes. Biochem. Biophys. Res. Commun. 75, 604-609

Goodman R.N., Kiraly Z. \& Wood K.R. (†986) The Biochemistry and Physiology of Plant Disease. University of Missoury Press, Columbia

Goossens J.F., Stabel A. \& Vendrig J.C. (1987) Relationships between kievitone and phaseollin accumulation in different tissues of Phaseolus vulgaris in response to treatment with mercuric chloride, a fungal cell wall elicitor and abscisic acid. Physiol. Mol. Plant Pathol. 30, 1-12

Gousseau H.D.M. \& Deverall B.J. (1987) Manipulation of the temperature-sensitive expression of the $\mathrm{Sr} 15$ allele conditioning resistance to stem rust in wheat. Physiol. Mol. Plant Pathol. 30, 157-165

Gracen V.E. (1982) Role of genetics in etiological phytopathology. Annu. Rev. Phytopathol. 20, 219-233

Grisebach H. \& Ebel J. (1978) Phytoalexins, chemical defense substances of higher plants? Angew. Chem. Int. Ed. Engl. 17, 635-647

Hahn M.G., Bonhoff A. \& Grisebach H. (1985) Quantitative localization of the phytoalexin glyceollin I in relation to fungal hyphae in soybean roots infected with Phytophthora megasperma f. sp. glycinea. Plant Physiol. 77, 591-601

Hamdan M.A.M.S. \& Dixon R.A. (1987) Differential patterns of protein synthesis in bean cells exposed to elicitor fractions from Colletotrichum lindemuthianum. Physiol. Mol. Plant Pathol. 31, 105-121

Harder D.E., Rohringer R., Samborski D.J., Rimmer S.R., Kim W.K. \& Chong J. (1979a) Electron microscopy of susceptible and resistant near-isogenic (sr6/Sr6) lines of wheat infected by Puccinia graminis tritici. II. Expression of incompatibility in mesophyll and epidermal cells and the effect of temperature on hostparasite interactions in these cells. Can. J. Bot. 57, 2617-2625

Harder D.E., Samborski D.J., Rohringer R., Rimmer S.R., Kim W.K. \& Chong J. (1979b) Electron microscopy of susceptible and resistant near-isogenic (sr6/Sr6) lines of wheat infected by Puccinia graminis tritici. III. Ultrastructure of incompatible interactions. Can. J. Bot. 57, 2626-2634

Hargreaves J.A. (1979) Investigations into the mechanism of mercuric chloride stimulated phytoalexin accumulation in Phaseolus vulgaris and Pisum sativum. Physiol. Plant Pathol. 15, 279-287

Hargreaves J.A. \& Bailey J.A. (1978) Phytoalexin production by hypocotyls of Phaseolus vulgaris in respon- 
se to constitutive metabolites released by damaged bean cells. Physiol. Plant Pathol. 13, 89-100

Harper S., Zewdie N., Brown I.R. \& Mansfield J.W. (1987) Histological, physiological and genetical studies of the responses of leaves and pods of Phaseolus vulgaris to three races of Pseudomonas syringæ pv. phaseolicola and to Pseudomonas syringæ pv. coronafaciens. Physiol. Mol. Plant Pathol. 31, 153-172

Heath M.C. (1982) The absence of active defense mechanisms in compatible host-pathogen interactions. In: Active Defense Mechanisms in Plants (Wood R.K.S., ed.). NATO Advanced Studies, Series A, Plenum Press, New York \& London, pp. 143-156

Heath M.C. (1986) Fundamental questions related to plant-fungal interactions: can recombinant DNA technology provide the answers? In: Biology and Molecular Biology of Plant-Pathogen Interactions (Bailey J.A. ed.). NATO ASI Series, Vol. 1, Springer-Verlag, Berlin, pp. 15-27

Hevesi M. \& Mashaal S.F. (1975) Contributions to the mechanism of infection of Erwinia uredovora, a parasite of rust fungi. Acta Phytopathol. Acad. Sci. Hung. 10, 275-280

Hohl H.R. \& Suter E. (1976) Host-parasite interfaces in a resistant and a susceptible cultivar of Solanum tuberosum inoculated with Phytophthora infestans : leaf tissue. Can. J. Bot. 54, 1956-1970

Ingham J.L. (1982) Phytoalexins from the Leguminosae. In: Phytoalexins (Bailey J.A. \& Mansfield J.W., eds). Blackie \& Son Ltd., Glasgow \& London, pp. 2180

Ingham J.L. \& Harborne J.B. (1976) Phytoalexin induc tion as a new dynamic approach to the study of systematic relationships among higher plants. Nature 260 , 241-243

Ingram D.S. (1982) A structural view of active defence. In: Active Defense Mechanisms in Plants (Wood R.K.S., ed.,). NATO Advanced Studies, Series A, Plenum Press, New York \& London, pp. 19-38

Johal G.S. \& Rahe J.E. (1988) Glyphosate, hypersensitivity and phytoalexin accumulation in the incompatible bean anthracnose host-parasite interaction. Physiol. Mol. Plant Pathol. 32, 267-281

Johnson L.E.B., Bushnell W.R. \& Zeyen R.J. (1979) Binary pathways for analysis of primary infection and host response in populations of powdery mildew fungi. Can J. Bot. 57, 497-511

Jørgensen H.J. \& Mortensen K. (1977) Primary infection by Erysiphe graminis f. sp. hordei of barley mutants with resistance genes in the $\mathrm{ml}-\mathrm{o}$ locus. Phytopathology 67, 678-685

Kaplan D.T., Keen N.T. \& Thomason I.J. (1980) Studies on the mode of action of glyceollin in soybean incompatibility to the root knot nematode Meloidogyne incognita. Physiol. Plant Pathol. 16, 319-325

Keen N.T. (1971) Hydroxyphaseollin production by soybeans resistant and susceptible to Phytophthora megasperma var. sojæ. Physiol. Plant Pathol. 1, 265275

Keen N.T. (1982) Specific recognition in gene-for-gene host-parasite systems. Adv. Plant Pathol. 1, 35-82 Keen N.T. (1986) Phytoalexins and their involvement in plant disease resistance. lowa State J. Res. 60, 477 499

Keen N.T., Érsek T., Long B., Bruegger B. \& Holliday M. (1981) Inhibition of the hypersensitive reaction of soybean leaves to incompatible Pseudomonas spp. by blasticidin $S$, streptomycin or elevated temperature. Physiol. Plant Pathol. 18, 325-337

Keppler L.D. \& Novacky A. (1987) The initiation of membrane lipid peroxidation during bacteria-induced hypersensitive reaction. Physiol. Mol. Plant Pathol. 30, 233-245

Kiraly Z. (1980) Defenses triggered by the invader: hypersensitivity. In: Plant Disease, vol. 5, How Plants Defend Themselves (Horsfall J.G. \& Cowling E.B., eds). Academic Press, New York, pp. 201-224

Kiraly Z., Barna B. \& Érsek T. (1972) Hypersensitivity as a consequence, not the cause, of plant resistance to infection. Nature $239,456-458$

Kono Y., Takeuchi S., Kodama O. \& Akatsuka T. (1984) Absolue configuration of oryzalexin A and structures of its related phytoalexins isolated from rice blast leaves infected with Pyricularia oryzæ. Agric. Biol. Chem. 48, 253-255

Kuc J. (1976) Phytoalexins and the specificity of plantparasite interaction. In: Specificity in Plant Diseases (Wood R.K.S. \& Graniti A., eds). NATO Advanced Studies, Series A, Plenum Press, New York \& London, pp. 253-268

Kuc J. (1982) Phytoalexins from the Solanaceæ. In: Phytoalexins (Bailey J.A. \& Mansfield J.W., eds). Blackie \& Son Ltd., Glasgow \& London, pp. 81-105

Kuc J. \& Rush J.S. (1985) Phytoalexins. Arch. Biochem. Biophys. 236, 455-472

Kuhn D.N. (1988) Plant stress responses: discussion of models for race-specific resistance. Recent Adv. Phytochem. 22, 127-161

Lazarovits G. \& Higgins V.J. (1976a) Histological comparison of Cladosporium fulvum race 1 on immune, resistant and susceptible tomato varieties. Can. J. Bot. 54, 224-234

Lazarovits G. \& Higgins V.J. (1976b) Ultrastructure of susceptible, resistant and immune reactions of tomato to races of Cladosporium fulvum.Can. J. Bot. 54, 235249

Lim S.M., Paxton J.D. \& Hooker A.L. (1968) Phytoalexin production in corn resistant to Helminthosporium turcicum. Phytopathology 58, 720-721

Lisker N. \& Kuc J. (1977) Elicitors of terpenoid accumulation in potato tuber slices. Phytopathology 67, 1356-1359

Long M., Barton-Willis P., Staskawicz B.J., Dahlbeck D. \& Keen N.T. (1985) Further studies on the relationship between glyceollin accumulation and the resistance of soybean leaves to Pseudomonas syringæ pv. glycienea. Phytopathology 75, 235-239

Loschke D.C., Hadwiger L.A. \& Wagoner W. (1983) Comparison of mRNA populations coding for phenylalanine ammonia lyase and other peptides from pea tissue treated with biotic and abiotic phytoalexin inducers. Physiol. Plant Pathol. 23, 163-173

Lucy M.C., Matthews P.S. \& Van Etten H.D. (1988) Metabolic detoxification of the phytoalexins maackiain and medicarpin by Nectria hæmatococca field isolates: relationship to virulence on chickpea. Physiol. Mol. Plant Pathol. 33, 187-199

Macfoy C.A. \& Smith I.M. (1979) Phytoalexin production and degradation in relation to resistance of clover leaves to Sclerotinia and Botrytis spp. Physiol. Plant Pathol. 14, 99-111

Maclean D.J., Sargent J.A., Tommerup I.C. \& Ingram 
D.S. (1974) Hypersensitivity as the primary event in resistance to fungal parasites. Nature 249, 186-187

Mansfield J.W. (1982) The role of phytoalexins in disease resistance. In: Phytoalexins (Bailey J.A. \& Mansfield J.W., eds). Blackie \& Son Ltd., Glasgow \& London, pp. 253-288

Mansfield J.W. (1983) Antimicrobial compounds. In: Biochemical Plant Pathology (Callow J.A., ed.). John Wiley \& Son, Chichester, pp. 237-265

Mansfield J.W. \& Widdowson D.A. (1973) The metabolism of wyerone acid (a phytoalexin form Vicia faba L.) by Botrytis fabæe and B. cinerea. Physiol. Plant Pathol. 3, 393-404

Mansfield J.W. \& Bailey J.A. (1982) Phytoalexins: current problems and future prospects. In: Phytoalexins (Bailey J.A. \& Mansfield J.W., eds). Blackie \& Son Ltd., Glosgow \& London, pp. 319-323

Marryat D.C.E. (1907) Notes on the infection and histology of two wheats immune to the attacks of Puccinia glumarum, yellow rust. J. Agric. Sci. 2, 129-138

Masri S.S. \& Ellingboe A.H. (1966) Primary infection of wheat and barley by Erysiphe graminis. Phytopathology 56, 389-395

Mayama S., Daly J.M., Rehfeld D.W. \& Daly C.R. (1975) Hypersensitive response of near-isogenic wheat carrying the temperature-sensitive Sr6 allele for resistance to stem rust. Physiol. Plant Pathol. 7, 35-47

Mayama S., Tani T., Matsuura Y., Ueno T. \& Fukami H. (1981) The production of phytoalexins by oats in response to crown rust Puccinia coronata f. sp. avenæ. Physiol. Plant Pathol. 19, 217-226

Mayama S. \& Tani T. (1982) Microspectrophotometric analysis of the location of avenalumin accumulation in oat leaves in response to fungal infection. Physiol. Plant Pathol. 21, 141-149

Mayama S., Hayashi S., Yamamoto R., Tani T., Ueno T. \& Fukami H. (1982) Effects of elevated temperature and $\alpha$-aminooxyacetate on the accumulation of avenalumins in oat leaves infected with Puccinia coronata f. sp. avenæ. Physiol. Plant Pathol. 20, 305-312

Mercer P.C., Wood R.K.S. \& Greenwood A.D. (1974) Resistance to anthracnose of French bean. Physiol. Plant Pathol. 4, 291-306

Meyer S.L.F. \& Heath M.C. (1988) A comparison of the death induced by fungal invasion or toxic chemicals in cowpea epidermal cell. 1. Cell death induced by heavy metal salts. Can. J. Bot. 66, 613-623

Moesta P. \& Grisebach H. (1981a) Investigation of the mechanism of phytoalexin accumulation in soybean induced by glucan or mercuric chloride. Arch. Biochem. Biophys. 211, 39-43

Moesta P. \& Grisebach H. (1981b) Investigation of the mechanism of glyceollin accumulation in soybean infected by Phytophthora megasperma f. sp. glycinae. Arch. Biochem. Biophys. 212, 462-467

Moesta P. \& Grisebach H. (1982) L-2-aminooxy-3-phenylpropionic acid inhibits phytoalexin accumulation in soybean with concomitant loss of resistance against Phytophthora megasperma f. sp. glycenae. Physiol. Plant Pathol. 21, 65-70

Moesta P., Seydel U., Lindner B. \& Grisebach H. (1982) Detection of glyceollin on the cellular level in infected soybean by laser microprobe mass analysis. Z. Naturforsch. 37c, 748-751

Molot P.M., Pochard E. \& Mas P. (1985) Le capsidiol conditionne-t-il la résistance du piment à Phytophtho- ra capsici ? Phytopathol. Mediterr. 24, 249-254

Müller K.O. (1959) Hypersensitivity. In: Plant Pathology, vol. 1, The Diseased Plant (Horsfall J.G. \& Dimond A.E., eds). Academic Press, New York, pp. 469-519

Müller K.O. \& Börger H. (1940) Experimentelle Untersuchungen über die Phytophthora -Resistenz der Kartoffel; Zugleich ein Beitrag zum Problem der "erworbenen Resistenz" im Pflanzenreich. Arb. Biol. Reichsanst. 23, 189-231

Ogle H.J. \& Brown J.F. (1971) Quantitative studies of the post-penetration phase of infection by Puccinia graminis tritici. Ann. Appl. Biol. 67, 309-319

Oku H., Shiraishi T., Ouchi S., Ishiura M. \& Matsueda R. (1980) A new determinant of pathogenicity in plant disease. Naturwissenschaften 67, 310-311

Oku H., Shiraishi T. \& Ouchi S. (1987) Role of specific suppressors in pathogenesis of Mycosphaerella species. In: Molecular Determinants of Plant Diseases (Nishimura S., Vance C.P. \& Doke N. eds.) Japan Scientific Societies Press, Tokyo, Springer-Verlag, Berlin, pp. 145-154

Paxton J.D. (1981) Phytoalexins. A working redefinition. Phytopathol. Z. 101, 106-109

Perrin D.R. \& Bottomley W. (1962) Studies on phytoalexins. V. The structure of pisatin from Pisum sativum L. J. Am. Chem. Soc. 84, 1919-1922

Populer C. (1978) Changes in host susceptibility with time. In: Plant Disease, vol. 2, How Disease Develops in Populations (Horsfall J.G. \& Cowling E.B., eds). Academic Press, New York, pp. 239-262

Pueppke S.G. \& Van Etten H.D. (1974) Pisatin accumulation and lesion development in peas infected with Aphanomyces euteiches, Fusarium solanif. sp. pisi, or Rhizoctonia solani. Phytopathology 64, 1433-1440

Pueppke S.G. \& Van Etten H.D. (1976) The relation between pisatin and the development of Aphanomyces euteiches in diseased Pisum sativum. Phytopathology 66, 1174-1185

Rahe J.E. (1973) Occurence and levels of the phytoalexin phaseollin in relation to delimitation at sites of infection of Phaseolus vulgaris by Colletotrichum lindemuthianum. Can J. Bot. 51, 2423-2430

Rathmell W.G. (1973) Phenolic compounds and phenylalanine ammonia lyase activity in relation to phytoalexin biosynthesis in infected hypocotyls of Phaseolus vulgaris. Physiol. Plant Pathol. 3, 259-267

Ravise A. \& Kirkiacharian B.S. (1976) Influence de la structure de composés phénoliques sur l'inhibition du Phytophthora parasitica et d'enzymes participant aux processus parasitaires. I. Isoflavonoïdes et coumestanes. Phythopathol. Z. 85, 74-85

Reisener H.J., Tiburzy R., Kogel K.H., Moerschbacher B. \& Heck B. (1986) Mechanism of resistance of wheat against stem rust in the Sr5/P5 interaction. In: Biology and Molecular Biology of Plant-Pathogen Interactions (Bailey J.A., ed.). NATO ASI Series, Vol. 1, SpringerVerlag, Berlin, pp. 141-148

Ricci P. (1986) Etude des relations hôte-parasite dans l'interaction compatible entre Dianthus caryophyllus $L$. et Phytophthora parasitica Dastur. Nature et intervention d'un mécanisme de défense élicitable. Thèse, Paris XI-Orsay

Rohringer R., Kim W.K. \& Samborski D.J. (1979) A histological study of interactions between avirulent races of stem rust and wheat containing resistance genes Sr5, Sr6, Sr8 and Sr22. Can. J. Bot. 57, 324331 
Rossall S., Mansfield J.W. \& Hutson R.A. (1980) Death of Botrytis cinerea and $B$. fabae following exposure to wyerone derivatives in vitro and during infection development in broad bean leaves. Physiol. Plant Pathol. 16, 135-146

Rouxel T. (1988) Pouvoir pathogène de Leptosphæria maculans et réaction hypersensible de Brassica $s p p$. Intervention d'une pathotoxine, la sirodesmine $P L$, et d'une phytoalexine, la brassilexine. Thèse, Paris XIOrsay

Rouxel T., Chupeau Y., Fritz R., Kollmann A. \& Bousquet J.F. (1988) Biological effects of sirodesmin PL, a phytotoxin produced by Leptosphæria maculans. Plant Sci. 57, 45-53

Rouxel T., Sarniguet A., Kollmann A. \& Bousquet J.F. (1989a) Accumulation of a phytoalexin in Brassica spp. in relation to hypersensitive reaction to Leptosphæria maculans. Physiol. Mol. Plant Pathol. (sous presse)

Rouxel T., Renard M., Kollmann A. \& Bousquet J.F. (1989b) Brassilexin accumulation and resistance to Leptosphærea maculans in Brassica spp. and progeny of an interspecific cross $B$. juncae $\times B$. napus. Sous presse (Euphytica).

Ryder T.B., Cramer C.L., Bell J.N., Robbins M.P., Dixon R.A. \& Lamb C.J. (1984) Elicitor rapidly induces chalcone synthase mRNA in Phaseolus vulgaris cells at the onset of the phytoalexin defense response. Proc. Natl. Acad. Sci. USA 81, 5724-5728

Ryder T.B., Bell J.N., Cramer C.L., Dildine S.L., Grand C., Hedrick S.A., Lawton M.A. \& Lamb C.J. (1986) Organization, structure and activation of plant defence genes. In: Biology and Molecular Biology of PlantPathogen Interactions (Bailey J.A., ed.). NATO ASI Series, Series H, Vol. 1, Springer-Verlag, Berlin, pp. 207-219

Sakai S., Doke N. \& Tomiyama K. (1982) Relation between necrosis and rishitin accumulation in potato tuber slices treated with hyphal wall components of Phytophthora infestans. Ann. Phytopathol. Soc. Jpn 48, 238-240

Sato N. \& Tomiyama K. (1976) Relationship between inhibition of intracellular hyphal growth of Phytophthora infestans and rishitin concentration in infected potato cells. Ann. Phytopathol. Soc. Jpn 43, 598-600

Sato N., Tomiyama K., Katsui N. \& Masamune T. (1968) Isolation of rishitin from tubers of interspecific potato varieties containing different late-blight resistance genes. Ann. Phytopathol. Soc. Jpn 34, 140-142

Sato N., Kitazawa K. \& Tomiyama K. (1971) The role of rishitin in localizing the invading hyphæ of Phytophthora infestans in infection sites at the cut surfaces of potato tubers. Physiol. Plant Pathol. 1, 289-295

Schmelzer E., Börner H., Grisebach H., Ebel. J. \& Hahlbrock K. (1984) Phytoalexin synthesis in soybean (Glycine max). Similar time courses of mRNA induction in hypocotyls infected with a fungal pathogen and in cell cultures treated with fungal elicitor. FEBS Lett. 172, 59-63

Sijpesteijn A.K. (1976) Induction of hypersensitive responses to fungal pathogens. In: Specificity in Plant Diseases (Wood R.K.S. \& Graniti A., eds). NATO Advanced Studies, Series A, Plenum Press, New York \& London, pp. 273-285

Skipp R.A. \& Deverall B.J. (1972) Relationships between fungal growth and host changes visible by light microscopy during infection of bean hypocotyls ( $P$ ha- seolus vulgaris) susceptible and resistant to physiological races of Colletotrichum lindemuthianum. Physiol. Plant Pathol. 2, 357-374

Skipp R.A. \& Samborski D.J. (1974) The effect of the Sr6 gene for host resistance on histological events during the development of stem rust in near-isogenic wheat lines. Can. J. Bot. 52, 1107-1115

Slesinski R.S. \& Ellingboe A.H. (1969) The genetic control of primary infection of wheat by Erysiphe graminis f. sp. tritici. Phytopathology 59, 1833-1837

Smith D.A. (1982) Toxicity of phytoalexins. In: Phytoalexins (Bailey J.A. \& Mansfield J.W., eds). Blackie \& Son Ltd., Glasgow \& London, pp. 218-252

Smith D.A., Wheeler H.E., Banks S.W. \& Cleveland T.E. (1984) Association between lowered kievitone hydratase activity and reduced virulence to bean in variants of Fusarium solani f. sp. phaseoli. Physiol. .Plant Pathol. 25, 135-147

Smith D.A. \& Banks S.W. (1986) Biosynthesis, elicitation and biological activity of isoflavonoid phytoalexins. Phytochemistry 25, 979-995

Stakman E.C. (1915) Relation between Puccinia graminis and plants highly resistant to its attack. J. Agric. Res. 4, 193-199

Stoessl A. (1980) Phytoalexins-a biogenic perspective. Phytopathol. Z. 99, 251-272

Stoessl A. (1983) Secondary plant metabolites in preinfectional and postinfectional resistance. $I n$ : The Dynamics of Host Defence (Bailey J.A. \& Deverall B.J., eds). Academic Press, Sydney, pp. 71-122

Strange R.N. (1987) High performance liquid chromatography of phytoalexins. In: High Performance Liquid Chromatography in Plant Sciences, Modern Methods of Plant Analysis, vol. 5 (Linskens H.F. \& Jackson J.F., eds). Springer-Verlag, Berlin, pp. 121-148

Sutton D.C. \& Deverall B.J. (1984) Phytoalexin accumulation during infection of bean and soybean by ascospores and mycelium of Sclerotinia sclerotiorum. Plant Pathol. 33, 377-383

Sweigard J.A. \& Van Etten H.D. (1984) Polar lipids from pea reduce the pisatin sensitivity of Aphanomyces euteiches. Phytopathology 74, 833

Takasugi M., Monde K., Katsui N. \& Shirata A. (1988) Novel sulphur-containing phytoalexins from the chinese cabbage Brassica campestris L. ssp. pekinensis (Cruciferæ). Bull. Chem. Soc. Jpn 61, 285-289

Tegtmeier K.J. \& Van Etten H.D. (1982) The role of pisatin tolerance and degradation in the virulence of Nectria hæmatococca on peas: a genetic analysis. Phytopathology 72, 608-612

Thurston J.D. (1971) Relationship of general resistance: late blight of potato. Phytopathology 61, 620-626

Tietjen K.G. \& Matern U. (1984) Induction and suppression of phytoalexin biosynthesis in cultured cells of safflower, Carthamus tinctorius L., by metabolites of Alternaria carthami Chowdhury. Arch. Biochem. Biophys. 229, 136-144

Touze A. \& Esquerre-Tugaye M.T. (1982) Defence mechanisms of plants against varietal non-specific pathogens. In: Active Defense Mechanisms in Plants (Wood R.K.S., ed.). NATO Advanced Studies, Series A, Plenum Press, New York \& London, pp. 103-117

Trivedi N. \& Sinha A.K. (1978) Production of a fungitoxic substance in rice in response to Drechslera infection. Trans. Br. Mycol. Soc. 70, 57-60 
Van der Plank J.E. (1982) Host-Pathogen Interactions in Plant Disease. Academic Press, New York

Van Etten H.D. (1973) Differential sensitivity of fungi to pisatin and to phaseollin. Phytopathology 63, 1477 1482

Van Etten H.D., Matthews P.S., Tegtmeier K.J., Dietert M.F. \& Stein J.I. (1980) The association of pisatin tolerance and demethylation with virulence on pea in Nectria hæmatococca. Physiol. Plant Pathol. 16, 257268

Van Etten H.D., Matthews D.E. \& Smith D.A. (1982) Metabolism of phytoalexins. In: Phytoalexins (Bailey J.A. \& Mansfield J.W., eds). Blackie \& Son Ltd, Glasgow \& London, pp. 181-217

Van Loon L.C. (1982) Regulation of changes in protein and enzymes associated with active defence against virus infection. In: Active Defense Mechanisms in Plants (Wood R.K.S., ed.). NATO Advanced Studies, Series A, Plenum Press, New York \& London, pp. 247. 273

Varns J.L. \& Kuc J. (1971) Suppression of rishitin and phytuberin accumulation and hypersensitive response in potato by compatible races of Phytophthora infestans. Phytopathology 61, 178-181

Varns J.L., Kuc J. \& Williams E.B. (1971) Terpenoid accumulation as a biochemical response of the potato tuber to Phytophthora infestans. Phytopathology 61, 174-177

Ward H.M. (1902) On the relations between host and parasite in the bromes and their brown rust, Puccinia dispersa (Erikss.). Ann. Bot. 16, 233-315

Ward E.W.B. (1986) Biochemical mechanisms involved in resistance of plants to fungi. In: Biology and Molecular Biology of Plant-Pathogen Interactions (Bailey J.A., ed.) NATO ASI Series, Series H, Vol. 1, SpringerVerlag, Berlin, pp. 107-131

Wilson U.E. \& Coffey M.D. (1980) Cytological evaluation of general resistance to Phytophthora infestans in potato foliage. Ann. Bot. 45, 81-90
Woods A.M., Fagg J. \& Mansfield J.W. (1988) Fungal development and irreversible membrane damage in cells of Lactuca sativa undergoing the hypersensitive reaction to the downy mildew fungus Bremia lactuca. Physiol. Mol. Plant Pathol. 32, 483-497

Yoshikawa M. (1978) Diverse modes of action of biotic and abiotic phytoalexin elicitors. Nature (Lond.) 275, 546-547

Yoshikawa M. (1983) Macromolecules, recognition, and the triggering of resistance. In: Biochemical Plant Pathology (Callow J.A., ed.). John Wiley \& sons, Chichester, pp. 267-298

Yoshikawa M., Yamauchi K. \& Masago H. (1978a) Glyceollin: its role in restricting fungal growth in resistant soybean hypocotyls infected with Phytophthora megasperma var. sojæ. Physiol. Plant Pathol. 12, 7382

Yoshikawa M., Yamauchi K. \& Masago H. (1978b) De novo messenger RNA and protein synthesis are required for phytoalexin-mediated disease resistance in soybean hypocotyls. Plant Physiol. 61, 314-317

Yoshikawa M., Yamauchi K. \& Masago H. (1979) Biosynthesis and biodegradation of glyceollin by soybean hypocotyls infected with Phytophthora megasperma var. sojæ. Physiol. Plant Pathol. 14, 157-169

Yoshikawa M., Masago H., Onoe T. \& Matsuda K. (1987) Mode of biochemical action of phytoalexins. In: Molecular Determinants of Plant Diseases (Nishimura S., Vance C.P. \& Doke N., eds). Jpn Scient. Soc. Press, Tokyo, Springer-Verlag, Berlin, pp. 253-267

Zacheo G. \& Bleve-Zacheo T. (1988) Involvement of superoxide dismutases and superoxide radicals in the susceptibility and resistance of tomato plants to Meloidogyne incognita attack. Physiol. Mol. Plant Pathol. 32, 313-322

Ziegler E. \& Pontzen R. (1982) Specific inhibition of glucan-elicited glyceollin accumulation in soybean by an extracellular mannan-glycoprotein of Phytophthora megasperma f. sp. glycinea Physiol. Plant Pathol. 20, $321-331$ 